\title{
Can Modification of Renal Replacement Therapy Improve the Outcome of Patients with Systemic Inflammatory Response Syndrome?
}

\author{
Andrew Davenport \\ University College London Centre for Nephrology, Royal Free Hospital, London, UK
}

The mortality of patients, both admitted to the intensive care unit (ICU) with acute renal failure (ARF), and those that develop ARF within the ICU, remains high. In a recent multinational survey of clinical practice in ICUs, the highest survival for ICU ARF was reported from Australia, which predominantly uses continuous haemofiltration [1]. Haemofiltration, a predominantly convective technique, removes more larger hydrophilic molecular weight compounds than diffusion-based haemodialysis. In the ICU setting, haemofiltration leads to greater cytokine removal, by a combination of membrane adsorption and convection [2], but does not remove bacterial endoand exotoxins. If haemofiltration techniques can remove some inflammatory mediators, then the question arises as to whether cytokine removal could influence patient outcome. In everyday clinical practice the amount of cytokines and other inflammatory mediators removed by standard haemofiltration systems is limited, dependent not only upon molecular size but also protein binding. To try and effect cytokine and other inflammatory mediator clearance, two small clinical studies used very high-volume haemofiltration exchanges, and reported a marked improvement in patient survival [3, 4]. A further trial by the Amsterdam group did not show any effect of the dose of haemofiltration delivered, or the timing of treatment initiation on patient survival [5]. Re-analysis of Honore's original study [4] showed that survival was greatest in those patients who were started on high-volume haemo- filtration within the first few hours of ICU admission. Looking at the time course of the inflammatory response then, there is a sequence of events leading to the activation of innate immunity through the Toll-like receptors and the production of pro-inflammatory cytokines and mediators, followed later by a corresponding increase in anti-inflammatory cytokines and mediators. Thus those studies, which used the very early initiation of high-volume haemofiltration, might have impacted on patients in the early pro-inflammatory phase of their illness, and so potentially altered their clinical course. Unfortunately, by the time most patients arrive in the ICU, or those who develop ARF in the ICU setting, the initial pro-inflammatory phase has passed, and patients have activation of both pro- and anti-inflammatory systems. In this phase of the illness, removal of cytokines and other mediators will be non-selective and may explain why the later start of high-volume haemofiltration has not been shown to improve patient outcomes [5].

High-volume haemofiltration, using standard commercially available sterile replacement fluids, is a complex treatment and is usually only performed for limited periods due to problems with circuit clotting, electrolyte, acid-base and thermal balance, and micronutrient losses. To try and achieve the same goals, other centres have developed high-volume exchanges based on haemodiafiltration using on-line ultrapure dialysis fluids, and this has been combined with daily plasma exchange [6]. This tech-

\section{KARGER \\ Fax +4161306 1234 E-Mail karger@karger.ch} www.karger.com
(C) $2006 \mathrm{~S}$. Karger AG, Basel 0253-5068/06/0243-0317\$23.50/0

Accessible online at: www.karger.com/bpu
A. Davenport

University College London Centre for Nephrology

Royal Free Hospital, Pond Street, London NW3 2QG (UK)

E-Mail andrew.davenport@royalfree.nhs.uk 
nique has been reported to improve the outcome of patients with acute liver failure [7], and is currently undergoing a multi-centre European clinical trial. As plasma products may be contaminated with blood-borne viruses and prions, other investigators have used coupled plasma filters with re-infusion of the filtrate, after adsorption. An alternative strategy has been to develop a very porous membrane designed to remove larger molecules up to and including albumin, so that both free and bound pro- and anti-inflammatory cytokines and other mediators can be removed without having to perform high-volume exchanges. Early animal experimental work, particularly during the pro-inflammatory phase of the illness, has been encouraging [8], and phase II clinical trials are currently under progress.

An additional strategy has been to add haemoperfusion to the haemofiltration circuit designed to remove hydrophobic mediators and toxins. Sorbents could potentially remove both Gram-negative lipopolysaccharide toxins and also Gram-positive exotoxins, in addition to both pro- and anti-inflammatory cytokines and other mediators [9]. Clinical studies have demonstrated that sorbent technology can significantly remove more cytokines compared to continuous haemofiltration. However, with current technology, cytokine removal is non-specific, for example resulting in similar removal of both pro-inflam- matory TNF- $\alpha$ and anti-inflammatory IL-10. The question arises as to whether new sorbents can be developed to target the removal of specific pathogenic toxins and other inflammatory mediators. Recent interest has centred on Gram-positive sepsis and the role of toxic shock syndrome toxin-1 (TSST-1), a superantigenic protein produced by Staphylococcus aureus which has been shown to produce multiple organ dysfunction in animal models similar to the human systemic inflammatory response syndrome [10]. Preliminary animal experiments have shown improved animal survival, using specially developed haemoperfusion sorbents designed to remove Gram-positive peptidoglycans, TSST-1 and Gram-negative endotoxins in a model of endotoxin/TSST-1-induced multiple organ dysfunction. Thus, sorbent technology, coupled with conventional haemofiltration, may potentially provide the basis for future treatments designed to alter the balance between pro- and anti-inflammatory mediators, and thus influence patient outcomes. However, to be most effective in the animal models, these treatments have to be started simultaneously with toxin administration, and clinical trials are therefore required to determine whether the addition of these newer sorbents to current haemofiltration therapies will alter the clinical outcome in patients with established systemic inflammatory response syndrome.

\section{References}

1 Uchino S, Kellum JA, Bellomo R, Doig GS, Morimatsu H, Morgera S, Schetz M, Tan I, Bouman C, Macedo E, Gibney N, Tolwani A, Ronco C, Beginning and Ending Supportive Therapy for the Kidney (BEST Kidney) Investigators: Acute renal failure in critically ill patients: a multinational, multicenter study. JAMA 2005;294:813-818.

2 Kellum J, Johnson J, Kramer D, Palevsky P, Brady JJ, Pinsky MR: Diffusive versus convective therapy: effects on mediators of inflammation in patients with severe systemic inflammatory response syndrome. Crit Care Med 1998; 26:1995-2000.

3 Oudemans-van Straaten HM, Bosman RJ, van der Spoel JI, Zandstra DF: Outcome of critically ill patients treated with intermittent highvolume haemofiltration: a prospective cohort analysis. Intensive Care Med 1999;25:814821.
4 Honore PM, Jamez J, Wauthier M, Lee PA, Dugernier T, Pirenne B, Hanique G, Matson JR: Prospective evaluation of short-term highvolume isovolaemic haemofiltration on the haemodynamic course and outcome of patients with intractable circulatory failure resulting from septic shock. Crit Care Med 2000; 28:3581-3587.

5 Bouman CS, Oudemans-Van Straaten HM, Tijssen JG, Zandstra DF, Kesecioglu J: Effects of early high-volume continuous venovenous haemofiltration on survival and recovery of renal function in intensive care patients with acute renal failure: a prospective, randomised trial. Crit Care Med 2002;30:2205-2211.

6 Oda S, Hirasawa H, Shiga H, Nakanishi K, Matsuda K, Nakamura M: Continuous haemofiltration/haemodiafiltration in critical care. Ther Apher 2002;6:193-198.

7 Sadamori H, Yaki T, Inagaki M, Shima Y, Matsuda H, Tanaka N, Sakaguchi K, Tsuji T, Matsumi M, Katayama H, Hirakawa N: Highflow-rate haemodiafiltration as a brain support therapy proceeding to liver transplantation for hyperacute fulminant hepatic failure. Eur J Gastroenterol Hepatol 2002;14:435-439.
8 Lee PA, Weger GW, Pryor RW, Matson JR: Effects of filter pore size on efficacy of continuous arteriovenous haemofiltration therapy for Staphylococcus aureus induced septicaemia in immature swine. Crit Care Med 1998;26:730_ 737

9 Winchester JF, Kellum A, Ronco C, Brady JA, Quartararo PJ, Salsberg JA, Levin NW: Sorbents in acute renal failure and the systemic inflammatory system. Blood Purif 2003;21: 79-84.

10 Miwa K, Fukuyama M, Matsuno N, Shimada K, Ikeda K, Ikeda T: Physiological response to superantigen-adsorbing hemoperfusion in toxin-concentration-controlled septic swine. Blood Purif 2006;24:319-326. 